\title{
THE IMPACT OF SCHOOL WORK QUALITY ON PUPILS
}

\author{
TASIC, I.; KARUOVIC, D. \& GLUSAC, D.
}

Abstract:This paper shows that self - valuation of pupils' work in school represents the best way for promotion of school work quality. In the paper are displayed the results of the research of the impact of school work activity on pupils' position in school through the valuation of four sub - scopes of valuation: taking care of pupils, learning support, personal and social development and professional orientation.

Key words: pupil, school, quality, evaluation
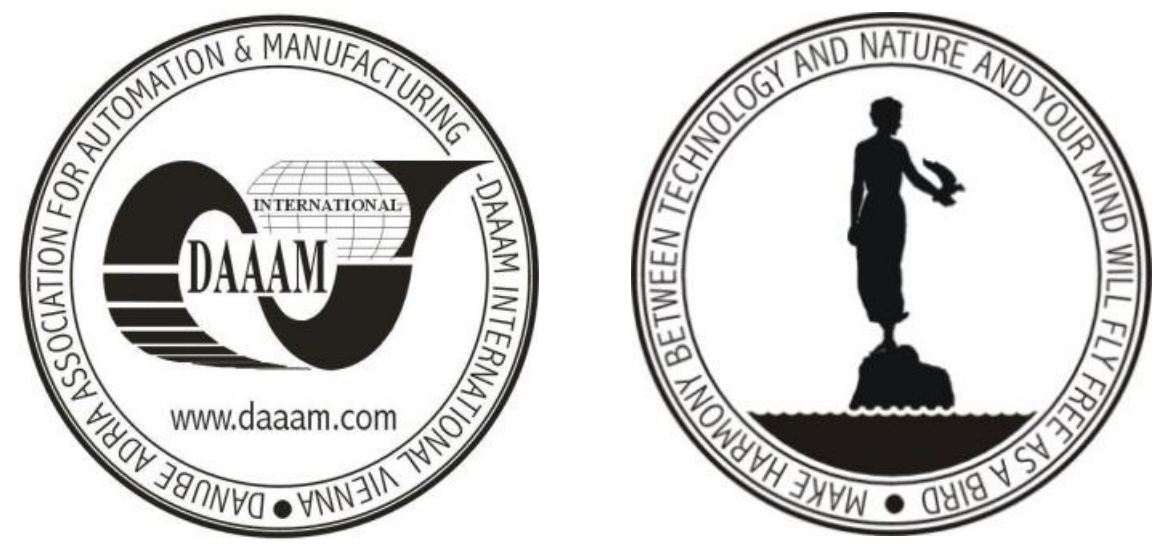

Authors' data: Dr. Sc. Tasic, I[van]; Dr. Sc. Karuovic, D[ijana]; Univ.Prof. Dr. Sc. Glusac, D[ragana], University of Novi Sad, Technical Faculty "Mihajlo Pupin“, Djure Djakovica BB, Zrenjanin, Serbia ivatasic@ptt.rs, aruena@tfzr.uns.ac.rs, gdragana@tfzr.uns.ac.rs

This Publication has to be referred as: Tasic, I[van]; Karuovic, D[ijana] \& Glusac, D[ragana] (2011). The Impact of School Work Quality on Pupils, Chapter 15 in DAAAM International Scientific Book 2011, pp. 181-194, B. Katalinic (Ed.), Published by DAAAM International, ISBN 978-3-901509-84-1, ISSN 1726-9687, Vienna, Austria

DOI: 10.2507/daaam.scibook.2011.15 


\section{Introduction}

When we speak about an educational institution culture, we usually connect it with school successfulness. Theoreticians often connect culture with values, and climate (a prevailing trend or current of feeling) with successfulness. Every institution is specific and they differ from others as well as every child starting its education distinguishes from an another child. School culture is a set of central values promoted by an institution, and which are deeply penetrated into the foundations of its life and work (Eisner, 1994.). When we speak about education, we have to mention that it is one of key factors of development for every society. Like every other field of social and economic life, it is necessary in educational processes to envisage work effects, in other words, quality of that work, and on the basis of achieved results to make an attempt to improve and enhance it. When we talk concretely about educational processes, it is indispensably to recognize the quality of educational activities and the quality of general and special conditions in which those activities happen. In order to advance the education process, it is necessary to evaluate it meeting high standards. The evaluation done with high grade, defines school current position, where it wants to be, what are the problems it faces and it gives constructive ideas how to solve those problems in the most effective and efficient way. The evaluation of school work can be done internally and externally. When we speak of the external or outside evaluation, we think about the inspection authorities that control how much the educational institution observes the entrance system components (curriculum, form, contents). The intern evaluation, the self evaluation process respectively, is practiced exclusively to developing aims. It is carried out in order to spur school promotion internally and externally as well for better planning and coverage on the level of local community, school and class itself. Within self - evaluation of an educational institution there are some key points as: what kind of school are we, how we know it, what con we do to be more better? To get answers to these and similar matters it is necessary to take appropriate actions in order to attain a detail self - analysis with the help of specially adapted questionnaries, to notice advantages, imperfections and potentials of the educational institution, then define development priorities and objectives. Self - evaluation enables schools to create their own development in compliance with their specific conditions and specific internal dynamics. As well every other institions, schools also have to be responsible for their own development, and have certain level of autonomy in that process. "Self - valuation exempts school from tension that appears as the consequence of external valuation as so far the only one form of attending and evaluating the work of educational - pedagogical institutions".( The Manual for Self - evaluation and valuation of school work, Belgrade, 2005). For the needs of this work we shall state key evaluation fields that are defined by the Department for education development and international educational cooperation:

1. School program and Annual work program

2. Teaching and learning

3. Pupils' achievements

4. Support to pupils 

5. Ethos
6. Resources
7. Management, organisation and quality raising and ensuring.

\section{Methodological outline of research}

\subsection{The problem and aim of research}

We shall speak in this paper of the fourth key field of evaluation: Support to pupils. Within this field one can separate four sub - fields:
a) care of pupils,
b) support to learning,
c) personal and social development,
d) professional orientation.

One can valuate their realization through next indicators:

a) Care of pupils. The aim is to determine are there safety and security of pupils in school as well is there followed physical, health and educational state of pupils, as well their social neds.

b) Support to learning. The aim is to ascertain is there an adequate quality of the offered programs for pupils' support, and also how is followed pupils' advance and success, and in the end how one can give professional help to teachers in providing support to pupils in learning process.

c) Personal and social development. The aim is to establish the fact is the school taking care of the personal and social life of pupils and how great is that care. As well the aim is to determine is there tolerance in school. Are there any support, cooperation and mutual respect as well is (there) with pupils developed responsibility for their own actions and self - confidence when one speaks about their knowlidge and capabilities.

d) Professional orientation. Its objective is to help disciples on the oceasion of deciding about creation of their professional path and making acquaintance with their future profession (pupils' informing in primary school with professions before enrolment in secondary schools, through organizing so - called "Open Doors Day", informing about characteristics of certain economic and social activities for which pupils are directed, about possibilities for education or employment after secondary schools).

\subsection{Instrument}

For research needs is composed a questionnaire consisting four sets of questions. These four sub - field questionnaire enquiries are taken to be valuated from the Manual for self - valuation and valuation of schoolwork.

\subsection{Sample}

The questionnaire was realized on the sample of 85 pupils of the primary school "Vuk Karadzich" in the village of Deronje. Four classes were surveyed (one class of every grade from the fifth up to eight grade). We strove to include into this 
Tasic, I.; Karuovic, D. \& Glusac, D.: The Impact of School Work Quality on Pupils

research the classes of various success structure (both "stronger"and "weaker"classes). When we take into consideration these factors, the sample can be considered as the representatieve model for the primary school "Vuk Karadzich"in Deronje.

\section{Future school}

Analysing the current, present forms of teaching in the world, including our country, it is evident that the teaching process, its forms, methods, modes and strategies are changing constantly, i.e. they are being adapted to new economic, technical, social and scientific changes, to the new conditions of conducting the learning process, new possibilities of contemporary educational technologies, new theories of learning, as well as the new insights into international relations and social systems.

This analysis shows that the earlier strategies, forms, modes and methods of conducting the teaching process have endured and are still going through the qualitative changes, which has led and still leads to the rise of new forms and methods of conducting the instruction. The future ways of realizing the teaching process will be characterized by the following changes:

1. Instead of the classical (traditional) way of teaching, appropriate environments and resources will be formed for independent and active learning, aided by the contemporary education technologies;

2. Instead of the previous all-inclusive organization and conducting of the teaching process, students are being directed towards the appropriate learning strategies and independent work aided by the educational technology;

3. Instead of adopting the prepared knowledge, the creation of personal knowledge is being stimulated, not based on the external leadership and action, but on the personal and internal motivation, interests, needs and intellectual capabilities;

4. Instead of one-way communication within the learning process, interactive relations and forms of learning, as well as models of teaching aided by the educational technology will be made possible;

Instead of linear (traditional) methods of learning, the non-linear, i.e. associative learning method aided by the multimedia, hypermedia and hypertext will be initiated. (Danilovic, 2011.)

Fast development of technologies has caused many changes in process of education itself. The future scholl will have a distance education Here are some of the questions that may appear during the creating the materials for distance learning:

- are the aims of distance learning program in accordance with the aims of institutions on which are they are carried out?

- How to realize administrative support?

- Do all the Universities have willingness to adopt distance learning system?

- How to protect copyrights?

- How to motivate the authors to submit their educational materials?

- How to direct a user to contents which are important for his education? 
- How to present the contents on the Internet?

- Which methods should be used in creating distance learning systems?

- How to qualify student' successes?

- Have the users got necessary background for distance learning?

- Which hardware platforms are necessary to users?

- Where to put educational contents? (Karuovic \& Radosav, 2009.)

\section{The results with discussion}

\subsection{Taking care of pupils}

Statement: I feel safe and secure in school.

$84,53 \%$ of the polled pupils feel safe and secure $(15,62 \%$ of them agree very much with the statement, and $68,91 \%$ agree). From $15,47 \%$ of the surveyed pupils which are not agreeable to the statement, only 5,6\% do not agree at all (fig. 1.).

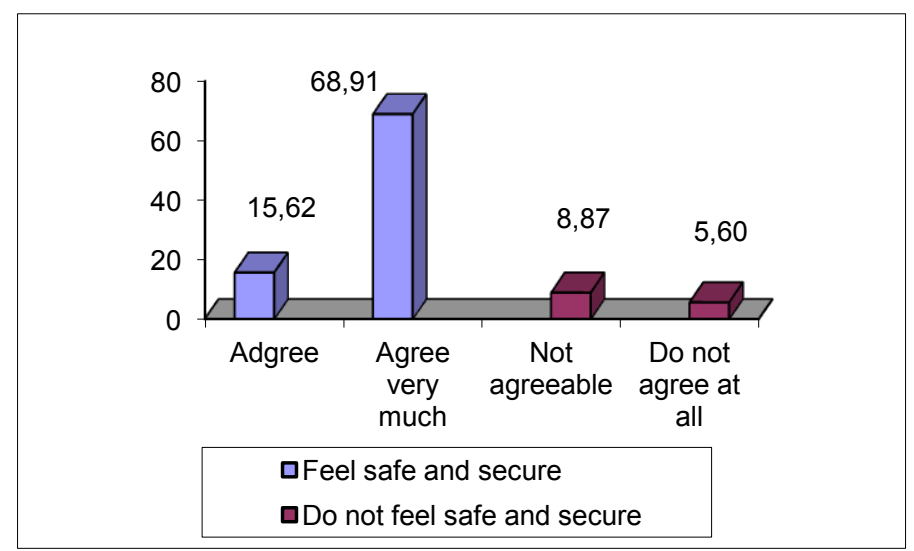

Fig.1. "I feel safe and secure in school." problems.

Statement: I know who to approach if I have emotional,health and social $47,3 \%$ of the respondents know who to consult if they have such needs, while 52,7\% do not know who to approach in such situations (fig.2).

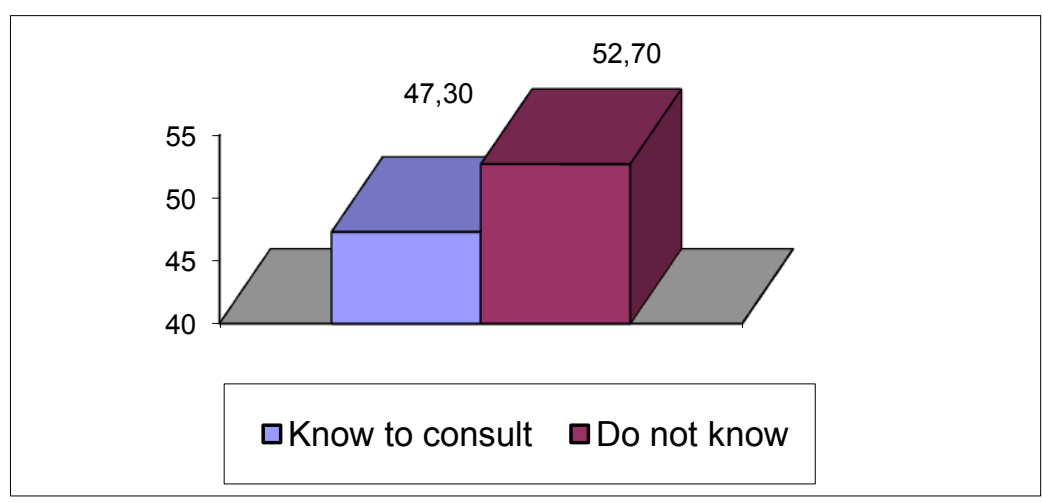

Fig.2. "I know who to approach if I have emotional,health and social problems"

Statement: The teachers, and especially the class - master are always ready to listen to my problems which are not directly connected with school 
$35,7 \%$ of the testees agree with the statement (only $8,2 \%$ are very agreeable with the statement), while $64,3 \%$ consider that the teachers are not always ready to listen to their problems which are not directly in connection with school (even 36,2\% don't generally agree with the statement, fig.3.).

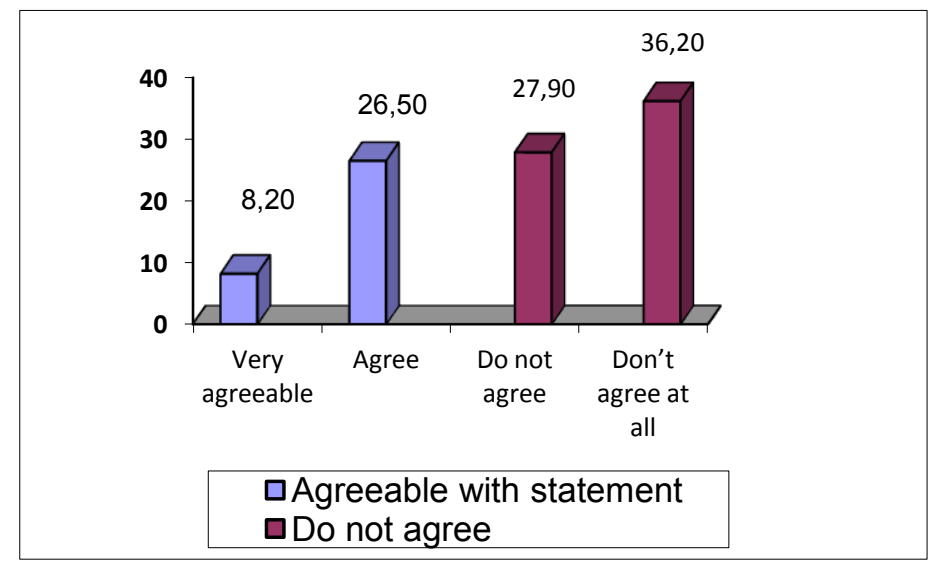

Fig. 3. "The teachers, and especially the class - master are always ready to listen to my problems which are not directly connected with school“"

Statement: The teachers, and especially the class - master are always ready to talk with my parents.

Only $11,8 \%$ of the examinees do not agree with the statement $(5,3 \%$ of them do not agree generally with the statement), while $88,2 \%$ of the examinees agree $(36,5 \%$ of them agree very much) with the offered statement (fig.4.).

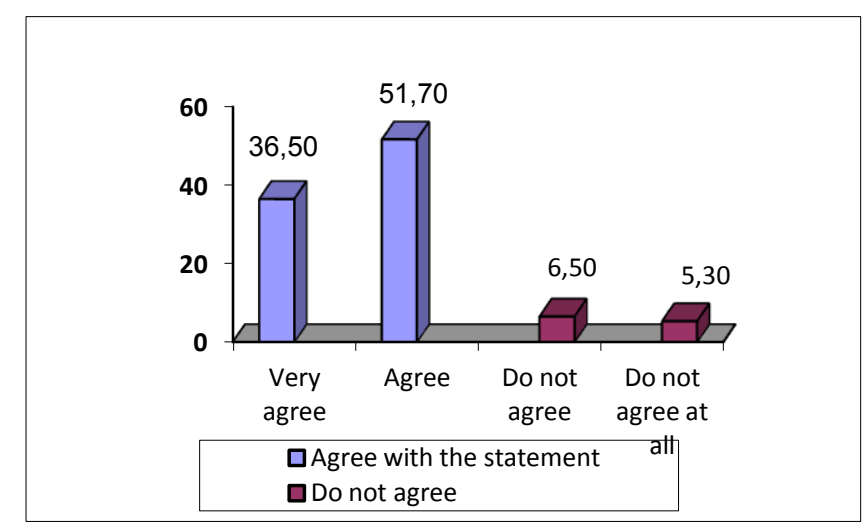

Fig. 4. "The teachers, and especially the class - master are always ready to listen to my problems which are not directly connected with school“"

There is the Book of pupils' safety in the polled school. It clearly states precise obligations and responsibilities of the employees in school, concerning pupils' safety and security. According to it a high percentage of the respondents in school feel safely. Also, a high percentage of the examinees know who to approach if their safety in school would be endangered. On the basis of these indicators one can conclude that the pupils' safety is satisfactory. The indicators relating to the following physical, emotional, health state and social needs, the teachers are ready at the most to cooperate with the parents, while the low percentage of pupils $(35,7 \%)$ finds that the 
teachers are ready to listen to their problems that have no direct connection with school. Some more examinees $(47,3 \%)$ know who to consult if they have health, emotional and similar problems. Althhough one can not state that the situation is alarming, it demands need for greater cooperation of the classmasters and vocational / expert service with disciples in order to promote health way of life and support to the pupils' development.

\subsection{Support to learning}

Statement: They teach us in school how to learn (they direct us into different / various learning techniques).

$38,6 \%$ testees agree with the statement that they are in school directed to diverse learning techniques, while $61,4 \%$ do not agree $(38,3 \%$ of them do not agree at all, fig.5.)

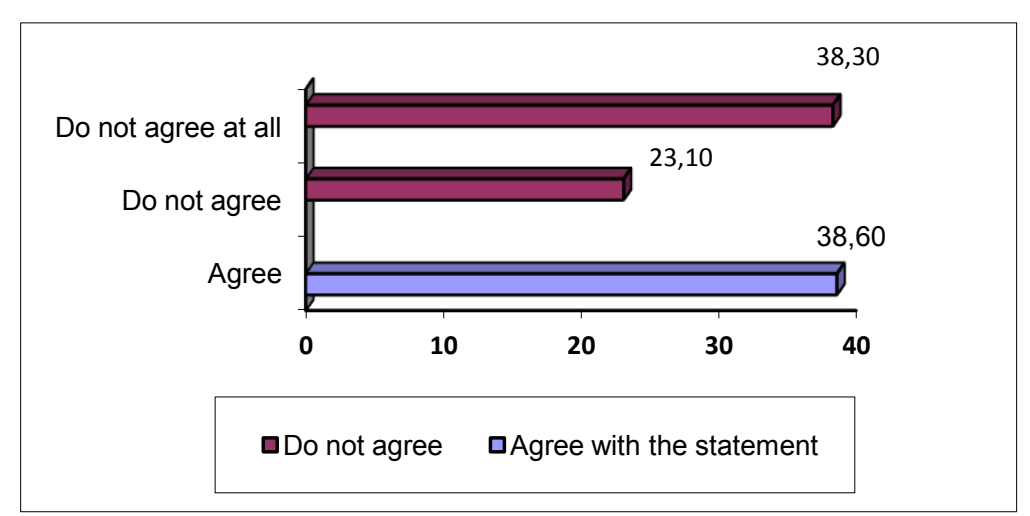

Fig. 5. "They teach us in school how to learn"

Statement: Pupils are not bored during classes.

$52,3 \% \%$ of the examinees agree with the assertion they do not feel bored at the classes (46,7\% of them very much agree), while $47,7 \%$ do not agree (fig.6.).

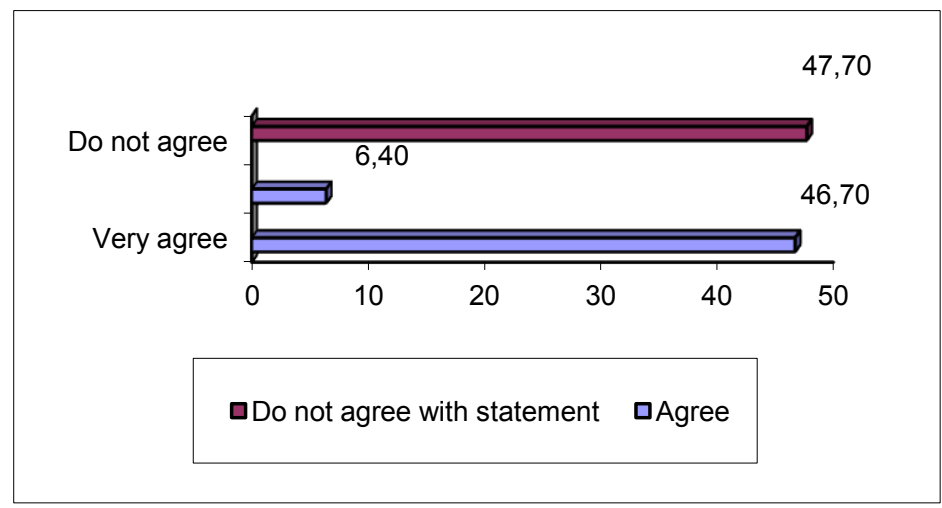

Fig. 6. "Pupils are not bored during classes"

Statement: I can work at the class as quickly as I want.

$59,6 \%$ agree with the assertion that at the class they can work as quickly, as they want (37,5\% agree very much), while $40,4 \%$ do not agree (28,3\% do not agree at all, fig.7.). 


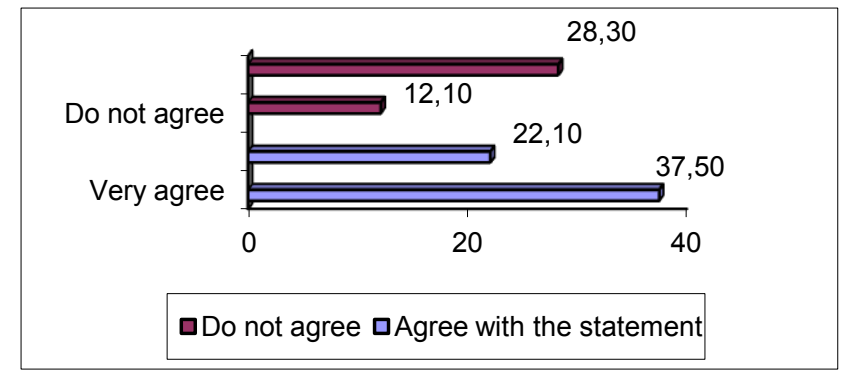

Fig. 7. "Pupils are not bored during classes"

Statement: When I have problems with learning in school, I can be advised how to overcome them.

The majority of the examinees $(76,35 \%)$ agree with the assertion that they have adequate support how to overcome their problems on the occasion of learning (46,2\% of them agree), while $23,65 \%$ do not agree, fig. 8 .

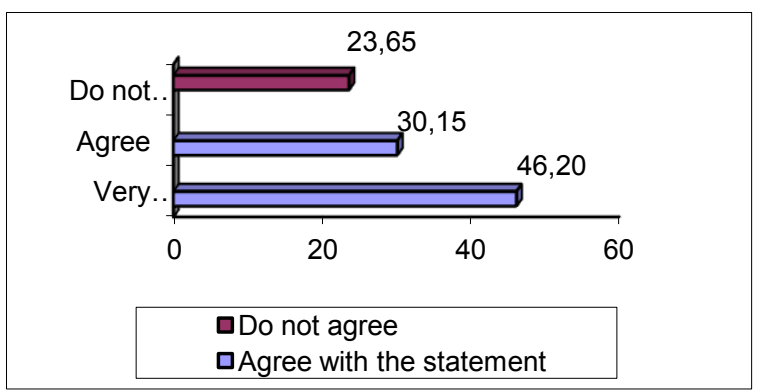

Fig. 8. "Pupils are not bored during classes"

In this set of indicators we can separate those ones which in the opinion of the surveyed pupils present the good features of the school and its downsides, in other words its advantages and disadvantages. There is relatively low percentage of respondents that agree with the assertion that they are taught in school by different teaching techniques. It is one of drawbacks, and they need to be enhanced. There is approximately the same number of pupils which feel bored and those ones which are not bored at the classes, so that we can take it as the difference in individual characteristics of pupils. 59,6\% of the testees agree with the assertion that they can work during classes so quickly as they wish.

We can find it as the fact how much are pupils interested in a subject or in which extent they are engaged at the classes. Praiseworthy is the fact that the majority of pupils (even 76,35\%) finds that they can be advised in school how to overcome problems that appear during learning / teaching. Consequently, the general conclusion is that the teachers should give more attention to the learning techniques the pupils apply. That is the statenent which had the lowest percent of accordance $(38,6 \%)$. Also, more attention should be given to those pupils who need more time to accomplish the tasks given at the class, so that they have enough time to do them, not to be bored during the class.

\subsection{Personal and social development}

Statement: We are taught at school to be responsible for learning. 
$79,64 \%$ of the examinees agree with the assertion that they are taught in school to be responsible, while $20,36 \%$ do not agree (fig.9.).

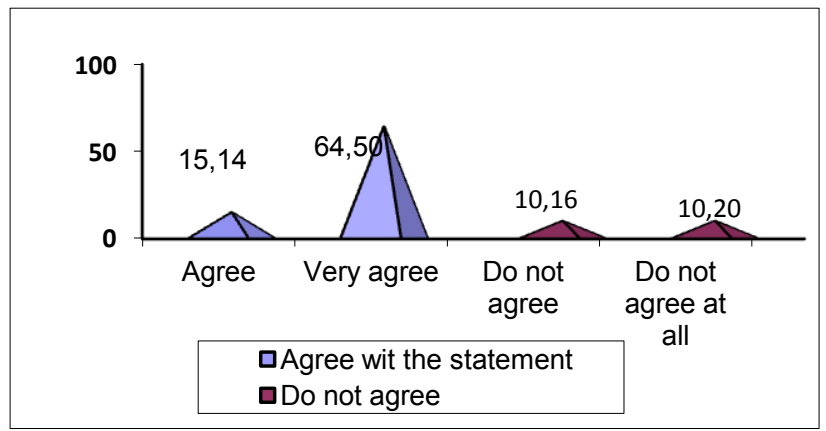

Fig. 9. "We are taught at school to be responsible for learning"

Statement: We are taught at school to be responsible for our behaviour and dealings.

$78,9 \%$ of the examinees agree with the assertion that they are taught at school to be responsible for their actions (67,4\% of them agree very much), while $21,1 \%$ do not agree (11,5\% do not agree at all, fig.10.).

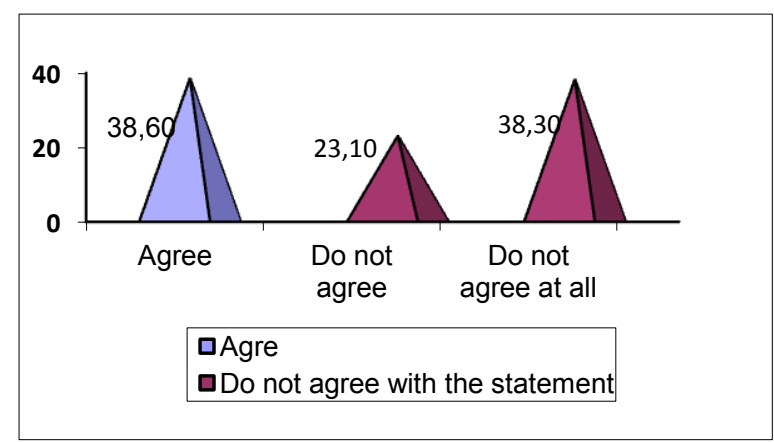

Fig. 10. "We are taught at school to be responsible for our behaviour and dealings"

Statement: We are at school stimulated / induced to come to conclusions and judgements independently and objectively, taking into consideration facts and source of information.

Very high percentage of respondents $(71,2 \%)$ agree with the assertion that they are taught at school to come open - mindedly and autonomously to judgements and conclusions, taking into consideration facts and source of information, while $28,8 \%$ do not agree (12,2\% do not agree at all, fig.11).

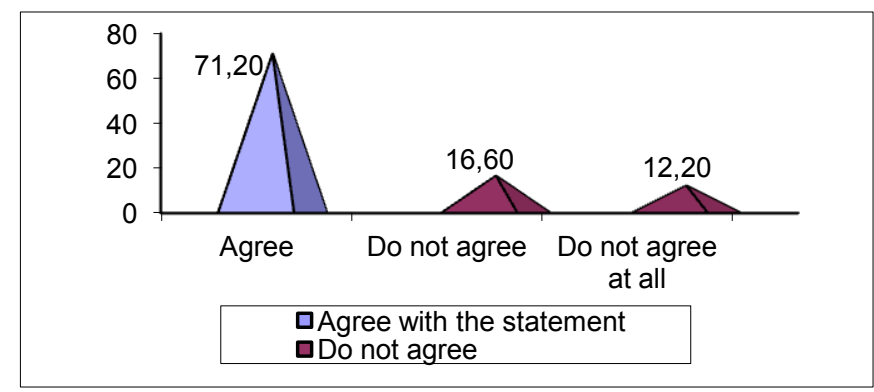

Fig. 11. "We are at school stimulated / induced to come to conclusions and judgements independently and objectively, taking into consideration facts and source of information“" 
Statement: We are stimulated to mutual tolerance at school.

$72,5 \% \%$ of the examinees agree with the assertion that they are in school stimulated to mutual tolerance, while $27,5 \%$ do not agree (fig.12.).

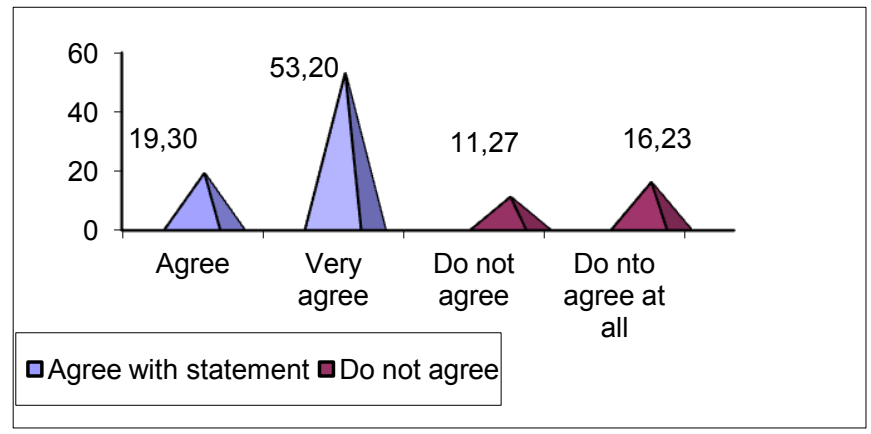

Fig. 12. "We are stimulated to mutual tolerance at school"

Statement: We are stimulated in school to take care of people.

$42,3 \%$ of the testees agree with the assertion that they are taught at school to take care of people $(27,4 \%$ of them agree very much), while $57,7 \%$ do not agree (22,4\% do not agree at all, fig.13.).

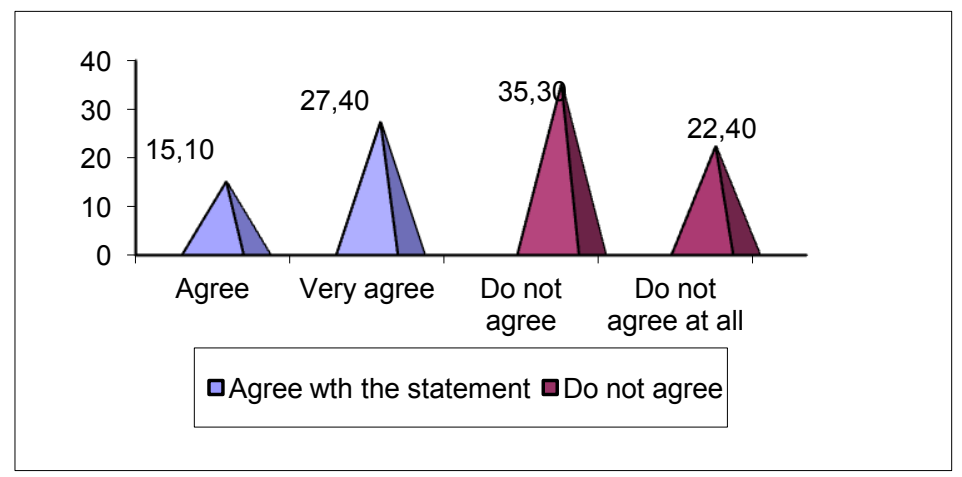

Fig. 13. "We are stimulated in school to take care of people"

Statement: Positive actions and sucess of pupils are regularly praised in school.

Majority of the examinees $(64,35 \%)$ agree with the assertion that positive actions and succes of pupils are regularly praised at schools $(57,6 \%$ of them agree very much), while minority of respondents, $35,65 \%$ do not agree $(16,7 \%$ of them do not agree at all, fig.14.).

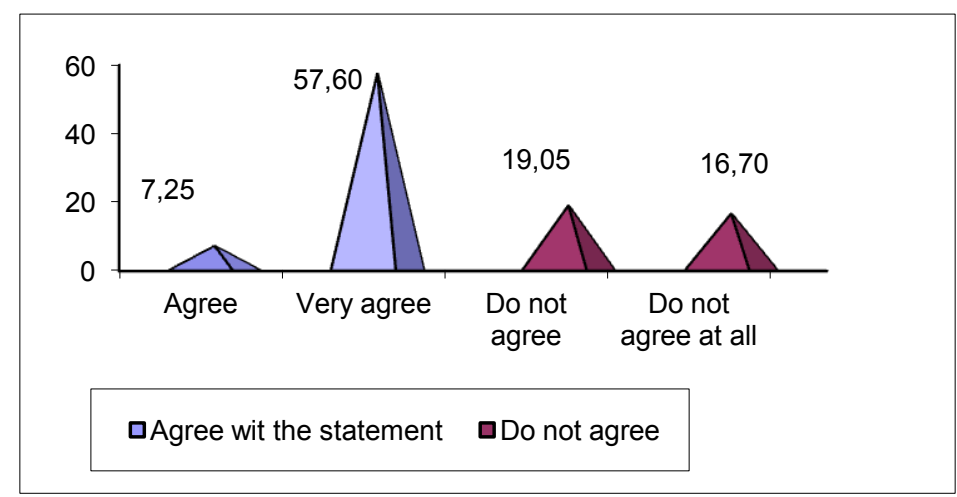

Fig. 14. "We are stimulated in school to take care of people" 
Statement: In school we are induced to respect diversities. $60,3 \%$ of testees agree with the assertion that they are at school induced to respect differences $(47,8 \%$ of them agree very much), while $39,7 \%$ do not agree $(13,4 \%$ of them do not agree at all, fig.15.).

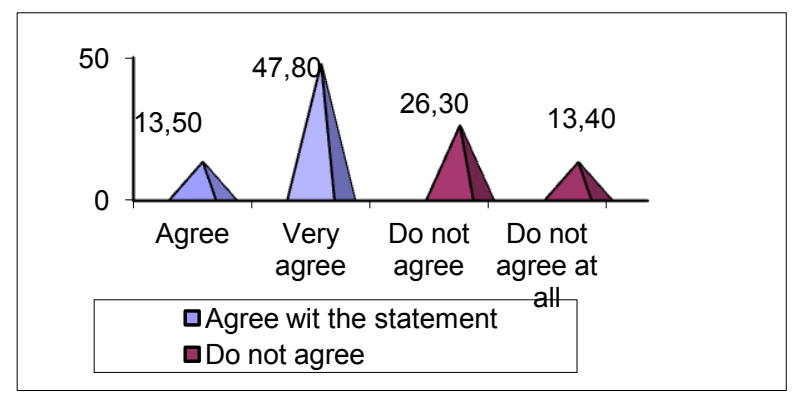

Fig. 15. "In school we are induced to respect diversities"

In view of these indicators one can conclude that it is necessary at school to take care to cherish positive social climate / atmosphere (mutual respect and esteem, inducing to cooperation and taking care of people). The pupils do agree with positive activity of the school on their personal and social development, but that they are not satisfied with some aspects. The weakest points in this field are insufficient inducing of pupils' initiative, mutual respect and esteem, inducing to cooperation and taking care of people. Disciples agree in high percentage with the assertion that teachers regularly praise their successes.

\subsection{Profesional orientation}

The primary school "Vuk Karadzich"visit representatives from different handicraft trades and industry. The pupils are also informed about the possibilities for enrolment into the wanted secondary schools. So, there is adequate cooperation with the representatives of the secondary schools. The pupils of this school receive and read materials related to the professional orientation through brochures, catalogues and the like. The school realizes the cooperation with parents because of individual advising for professional orientation of every child apart.

Statement: We are informed through talks at school about the possibilites how to continue our schooling.

$67,5 \%$ of the examinees agree with the assertion that they are informed in school about the posibilities how to continue their schooling through conversations (56,4\% of them agree very much), while $32,5 \%$ do not agree $(12,7 \%$ of them do not agree at all, fig.16.).

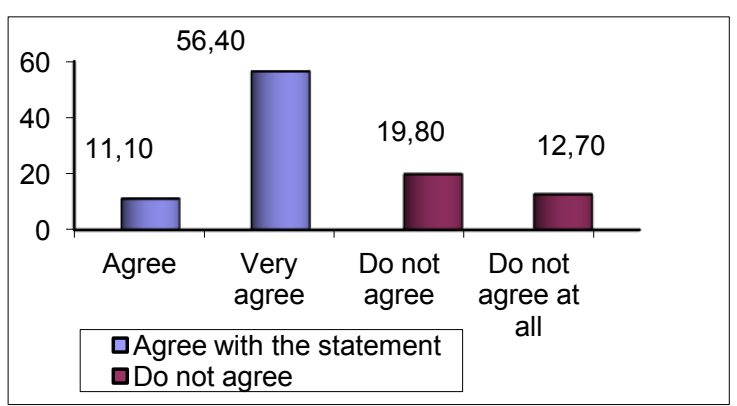

Fig. 16. "We are informed through talks at school about the possibilites how to continue our schooling" 
Tasic, I.; Karuovic, D. \& Glusac, D.: The Impact of School Work Quality on Pupils

Statement: There are at school at our disposal informative materials about further forms of schooling.

Approximately the same number of respondents $(65,4 \%)$ agree with the assertion that they have in school at their disposal informative materials about further forms of schooling $(53,8 \%$ of them agree very much), while the minority of testees $34,6 \%$ do not agree (fig.17.).

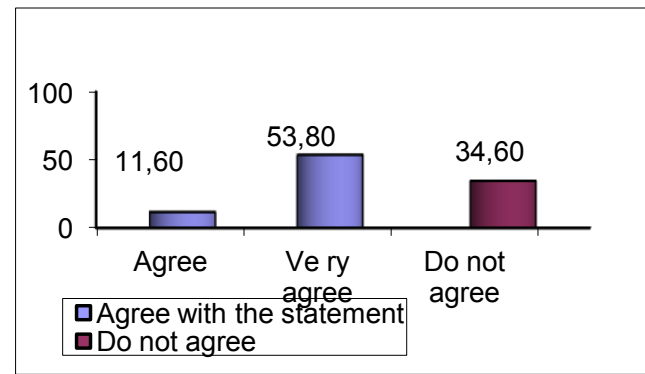

Fig. 17. "There are at school at our disposal informative materials about further forms of schooling"

Statement: They can be advised at school for the choice of their next school. Majority of the examinees $(68,64 \%)$ agree with the assertion that they can get at school advices related to the choice of their future school (47,3\% agree very much), while minority of the testees, $31,36 \%$ do not agree (fig.18.).

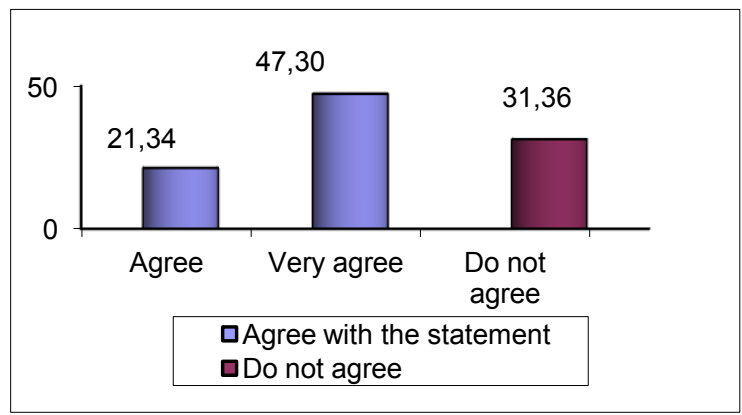

Fig. 18. "They can be advised at school for the choice of their next school"

Statement: I am satisfied with quality of the available information and consultations.

Roughly the same number of the respondents $(66,8 \%)$ agree with the assertion that they are satisfied with quality of the obtainable information and consultations they get at school (58,3\% of them agree very much), while $33,2 \%$ do not agree (18,2\% do not agree at all, fig.19.).

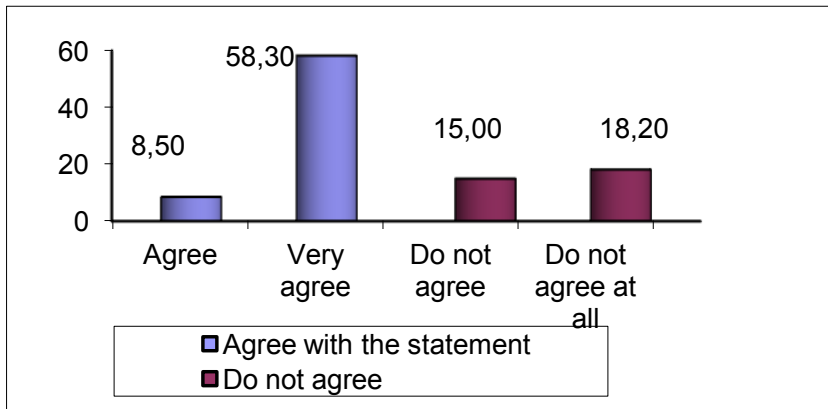

Fig. 19. "I am satisfied with quality of the available information and consultations" 
On the basis of the obtained indicators, we can conclude that pupils in schools receive enough information referred to their professional orientation and related to their decision which secondary school they will enroll. The pupils have at their disposal directories, catalogues and brochures, which can inform them about the schools that are in the sphere of their interest. Also, the pupils are welcome to address their teachers at school and ask their advice and help related to their professional orientation. High percentage of pupils is satisfied with quolity of the obtainable information and consultations.

\section{Further research}

The school should give attention to encourage children to take care of people, because the fewer percentage of the surveyed children consider that stimulus is omitted. On the other side the pupils at the school are induced to respect varieties, and it presents the imperative of our times The future research should test the pupils satisfaction with quolity of the obtainable information and consultations. Further researches will certainly lead to practical and scientific contributions.

What we all need in our further work is to expand the researches to even bigger circle of users with the material and technical support of competent ministry and other institutions in the social community.

\section{Conclusion}

The pupils' survey as a procedure (form) of self - valuation is used in this paper. For every subfield are indicated good features and downsides the school need to considerate. From those data we can perceive schoolwork quality, too. One of important school qualities is that pupils in it feel safely. Also, the majority of the surveyed pupils know who to address if their safety is in any way threatened. The results of reserach shows that fewer number of pupils know who to address if they have certain emotional, health and social needs. As the problem or downside / weakness of the school is the fact that the low percentage of pupils agree with the assertion that teachers are always ready to listen to their problems, although they do not have direct connection with school. In accordance with this indicator teachers would give more attention to pupils' needs outside school, because just these problems can potentially have an effect on their work and success at school, as well on their emotional condition.

This research indicates also that the pupils need help on the occasion of learning, so the school need to introduce various support programs for the pupils during learning process (the majority of polled pupils agree with the assertion that they are not sufficiently acquainted with various learning techniques. What is considered the strong side of the school (good features) is that pupils think that they are taught in school to be responsible for learning and their own actions. High 
percentage of pupils consider that they are at school stimulated to make decisions independently.

They are also motivated to mutual tolerance, and it is very praiseworthily for the school. The subfield that satisfies pupils at the most is the one referring to professional orientation. The pupils are safisfied with the quantity and quality of information about further possibilities of schooling, which they are given at school. High percentage of pupils also think that they are given all necessary advices related to the next school choice.

In view of all above mentioned, we can conclude that at the school the teachers' first concern are children as well their professional orientation, although we have to emphasize that at the school in accordance with the mentioned indicators, there is positive social climate.

Studies, like this, are of big help to rise a scholl work quality at all.

\section{References}

Bezinović, P. (2010). Self - valuation in the function of school quality promotion, www.idi.hr/valuation

Danilovic, M. (2011). School For The Future - Where and How, International conference on Information technology and Development of education - ITRO 2011, pp.118-123 ISBN: 978-86-7672-134-4, Technical Faculty "Mihajlo Pupin", Zrenjanin

Fullan,M. (2006): Learing Places,A Field for Improving the Context of Shooling, London:Sage Publications

Karuovic, D. \& Radosav, D. (2009). User Interface Design in Distance Learning System, Chapter 08 in DAAAM International Scientific Book 2009, pp. 061070, B. Katalinic (Ed.), Published by DAAAM International, ISBN 978-3901509-69-8, ISSN 1726-9687, Vienna, Austria, DOI: 10.2507/daaam.scibook.2009.08

*** Ministry of Education and Sport (2002). Qualitative education for all the way to developed society, Belgrade

*** Ministry of Education and Sport. (2005). Manual for Self - valuation and schoolwork valuation, Belgrade 